\title{
ESTUDO ETNOGRÁFICO SOBRE O CAMPO DA TATUAGEM NA CIDADE DE CASCAVEL - PR
}

\author{
Por Ana Cristina Bochnia Cabral ${ }^{1}$
}

\begin{abstract}
Resumo
A pesquisa desenvolvida trata-se de uma descrição etnográfica sobre o campo da tatuagem na cidade de Cascavel/Paraná, com o intuito de trazer luz às representações acionadas nas relações sociais dentro do campo. Para realizá-la, utilizei a metodologia da etnografia. Verificou-se que, em meados dos anos 80 os estúdios receberam uma normatização sanitária que permitia se estabelecerem como legais perante o Estado. Os principais resultados obtidos com a pesquisa demonstram que tatuadores passaram a ser vistos como profissionais em decorrência de uma série de regulamentações em relação aos estúdios e na entrada de novos materiais e métodos mais sofisticados no Brasil. A higiene é também adotada como reforço da representação de profissional. Chancelados pelo Estado, os tatuadores profissionais projetam em sua prática a assepsia necessária e não presente nos ilegais. No entanto, a condição higiênica de profissional concorre com a auto-representação de artista, gerando reações de valorização das expressões artísticas em detrimento das não profissionais-higiênicas. Este campo se organiza de forma dual, tais sejam: profissionais e não-profissionais, artistas e amadores, legais e ilegais. A valorização da técnica, da higiene e assepsia, e sobretudo do caráter artístico do trabalho são os principais suportes dessa dualidade no campo entre os tatuadores.
\end{abstract}

Palavras-chave: Antropologia Urbana, tatuagem, Tatuadores.

\begin{abstract}
The research developed it is an ethnographic description of the field of tattooing in the city of Cascavel / Paraná, in order to bring light to the representations activated in the social relations within the field. To do it, I used the methodology of ethnography. It was found that in the mid-80s the studios received a health regulation that allowed establish legal before the state. The main results obtained from the research show that tattoo artists were seen as professionals as a result of a series of regulations in relation to the studios and the entry of new materials and more sophisticated methods in Brazil. Hygiene is also adopted in furtherance of professional representation. Chancelados State, tattooists design professionals in their practice asepsis and not necessary in this illegal. However, the hygienic condition of professional competes with self-representing artist, generating reactions appreciation of artistic expression at the expense of non-professional hygienic. This field is organized in a dual way, such as: professional and non-professional artists and amateurs, legal and illegal. The valuation technique, hygiene and asepsis, and especially the artistic character of labor are the mainstays of this duality in the field of tattoo artists.
\end{abstract}

Keywords: Urban Antropology, Tattoo, Tattoists

\footnotetext{
${ }^{1}$ Mestrando de Ciências Sociais da Unioeste Toledo/PR. Este artigo é oriundo de meu Trabalho de Conclusão de Curso intitulado: Arte na Pele: estudo sobre o campo da tatuagem na cidade de Cascavel PR, apresentado à Coordenação do Colegiado do Curso de Ciências Sociais da Universidade Estadual do Oeste do Paraná - UNIOESTE, Campus de Toledo, orientado pelo Prof ${ }^{\circ}$. Dr. Allan de Paula Oliveira.
} 


\section{INTRODUÇÃO}

Antes de apresentar este trabalho, abordo brevemente à história da tatuagem, o que proporcionará um melhor entendimento no decorrer do texto. Para isso utilizei-me do livro de Toni Marques (1997), intitulado “O Brasil Tatuado e Outros Mundos”, onde o autor expõe uma evidência concreta da prática da tatuagem na pré-história através das evidências encontradas no famoso "homem do Gelo" que, em 1991, foi achado numa cidade da Itália e foi datado de 5.300 a. C. ${ }^{2}$. O costume, ou a arte de marcar o corpo foi identificado no antigo Egito em 400 a. C. e nas civilizações chamadas pré-colombianas no começo da era Cristã. Há relatos de que no período de Inquisição também havia esta prática, mas fora banida.

A tatuagem também foi, e pode se dizer que ainda é, uma prática central em muitas culturas. É o que ocorreu, por exemplo, em diversas sociedades polinésias, do Oceano Pacífico. Por exemplo, os Maori usavam esta prática como ritual de iniciação para a vida adulta, onde faziam marcas nos seus corpos e até mesmo em seus rostos. Para isso, se utilizavam de ossos pontiagudos. Tatuar-se era, para os Maori, um ritual de transformação do "menino" em "guerreiro". Segundo Marques, os marinheiros que exploravam o Oceano Pacífico, no século XVII, ficaram tão encantados com a prática da tatuagem entre os Maori que aderiram a este costume também. Com isso, trouxeram essa prática para os portos dos países europeus.

Embora a prática da tatuagem no ocidente remonte desde o século XVII, a gênese da palavra tatuagem provém do século XVIII, oriunda do inglês "tattoo", através da palavra "tattow" escrita no diário do capitão James Cook, um pioneiro da navegação, morto em 1779 num confronto entre nativos do Havaí ${ }^{3}$.

No início do século XX, tendo a tatuagem como uma prática social de "portos" tornou-se mais popular entre americanos e europeus, surgindo assim um mercado para os tatuadores, tendo uma boa clientela já a partir da década de 1950.

\footnotetext{
${ }^{2} \mathrm{O}$ "homem de Gelo" possuía tatuagens na região lombar, no tornozelo e também no joelho.

3 A viagem de James Cook ao arquipélago havaiano foi objeto de análise antropológica por parte de Marshall Sahlins em Ilhas de História. Descobri-lo como personagem ilustre da história da tatuagem no ocidente foi uma agradável surpresa para mim. SAHLINS (1990).

${ }^{4}$ Prática essa tida pelos frequentadores, ou seja, viajantes, marinheiros, trabalhadores, pescadores entre outros que se utilizavam dos serviços portuários frequentemente. Assim, a prática da tatuagem tornou-se mais visível socialmente.
} 
No Brasil não foi muito diferente, embora não existam dados precisos sobre a data de seu surgimento. O que há são evidências de que antes da chegada dos portugueses os índios já praticavam o costume de pintar o corpo, em um fenômeno semelhante à tatuagem. O urucum e o jenipapo forneciam as tintas utilizadas para a pintura ${ }^{5}$. A tatuagem, propriamente dita, tomou destaque a partir do século XIX com a abertura dos portos, onde a mistura dos povos do litoral com os marinheiros fez com que a tatuagem virasse um atrativo para as camadas baixas. Assim, marinheiros, meretrizes e outros grupos marginalizados foram "seduzidos" por esta prática.

A história da tatuagem no Brasil tem um momento importante em 1959, quando da chegada de um dinamarquês conhecido como "Lucky Tattoo", cujo nome era Knud Harld Likke Gregersen. Lucky é reconhecido pelos tatuadores no Brasil como o fundador da prática profissional da tatuagem. Seu trabalho tornou-se popular no início dos anos 1970 quando atores e músicos apareceram com tatuagens.

Nesta mesma época as pessoas adeptas à prática da tatuagem eram em sua maioria grupo de roqueiros, assim como o movimento hippie, dentre outros. Todos com um "mesmo sentido": mostrar a diferença, usando a tatuagem como um modo de recusa ao "sistema". Deste modo, o uso da tatuagem por esses jovens, tidos como "rebeldes", só veio acentuar a relação da tatuagem com a marginalidade e a criminalidade. Por outro lado, fez da tatuagem uma prática um pouco mais difundida entre jovens de classe média.

Nas últimas duas décadas nota-se uma popularização ainda maior da tatuagem, o que deriva por um lado da representação estética de setores de elite cultural, e por outro das aspirações ao status de arte dos próprios tatuadores. No caso da prática profissional da tatuagem, além da evolução técnica dos desenhos e equipamentos utilizados, houve também as regulamentações e permissões estatais à pratica.

A popularização destas marcas corporais gera reações ambíguas de tatuados e tatuadores, as quais explorei mais detidamente durante os capítulos etnográficos. Essas reações envolvem o otimismo diante de uma perspectiva de "normalização" da prática, apontando uma suposta "evolução social", que aceita a tatuagem. Numa outra perspectiva há o risco da vulgarização de uma prática considerada artística; essa reação está ligada a

\footnotetext{
${ }^{5}$ As tintas extraídas dessas árvores são utilizadas e comercializadas até hoje no Brasil e no mundo. As sociedades indígenas brasileiras, em grande medida, não praticam tatuagem, no sentido explícito do termo, mas sim a prática da pintura corporal - a diferença entre ambas é a permanência do desenho, presente na primeira e ausente na segunda. Contudo, uma comparação entre ambas práticas pode ser interessante. Sobre as práticas das pinturas corporais em sociedades indígenas brasileiras, cf. os ensaios reunidos em Vidal (2002).
} 
uma representação da tatuagem ligada à pureza da arte, que estaria ficando mais comercial e de consumo. Além disso, a perspectiva de mudanças ameaça discursos de hegemonia e representa possibilidades de ascensão no campo da tatuagem.

Devido a todos estes elementos, a tatuagem se apresenta como um tema para ser estudado nas ciências sociais dentro de um sentido mais amplo. Para isso creio ser profundamente importante a compreensão da noção de corpo, à medida que a tatuagem consiste numa técnica que tem o corpo como suporte, ou seja, a prática da tatuagem envolve também representações sobre o corpo.

Este artigo é um pequeno recorte de uma pesquisa bem mais ampla realizada entre meados de 2010 e final 2011, o qual possibilitou conhecer como acontecem as relações sociais dentro do campo da tatuagem na cidade de Cascavel.

\section{CONHECENDO O CAMPO}

A pesquisa abrangeu um total de seis estúdios ${ }^{6}$. No desenvolvimento de minha pesquisa, o primeiro passo dado foi no sentido do levantamento de material bibliográfico sobre tatuagem. Num segundo momento iniciei as idas regulares no campo préestabelecido. Nelas fiz uso de caderneta e diário de campo, observação participante, além de conversas informais que permitiram uma análise mais neutra dos discursos acionados pelos agentes.

Em tal estudo deparei-me com a riqueza na trajetória de vida dos tatuadores e a trajetória desses em direção à aquisição da técnica e da legalização dessa atividade. $\mathrm{O}$ ponto de partida desta investigação foi um estúdio localizado no centro da cidade de Cascavel, Paraná. Ao longo de minha pesquisa o campo foi se abrindo, tornando perceptível, quando comecei as anotações em minha caderneta, a localização geográfica dos estúdios. Esses "mais conhecidos"

A partir dessas constatações direcionei meu foco de pesquisa para o campo da tatuagem. Por fim, o objetivo central desta pesquisa foi analisar o campo da tatuagem em

\footnotetext{
6 Optei por utilizar a palavra "estúdio" por ser uma categoria recorrente entre os pesquisados. Nas bibliografias e termo também é utilizado em inglês "Studio" e em outros de "Atelier", "Salão" dentre outros. O termo "estúdio" designa em alguns países europeus a lugares associados com a prostituição e entre outros lugar é usado para designar o locar de gravações de música, aqui nesse caso particular, o termo "estúdio" é utilizado para representar o ambiente onde os tatuadores desenvolvem seu trabalho.

7 Trago aqui a expressão "os estúdios mais conhecidos" por que quando comecei a pesquisa em um ambiente logo obtive informações de outros, e, conforme ia conhecendo e tendo contato com os outros estúdios classifiquei-os como sendo mais conhecidos. Esse campo se mostrou como uma rede repleta de significados a partir do momento em que ia tendo mais contato com ele.
} 
Cascavel/Paraná, que tem como atores principais os tatuadores. Através da articulação da bibliografia e da análise dos dados obtidos para a compreensão da prática da tatuagem descrevo as relações entre os tatuadores e relações de poder que uns exercem sobre os outros, bem como, a organização do espaço ocupado por eles.

A fim de delimitar o "campo da tatuagem” utilizei-me da definição de Bourdieu:

Em termos analíticos, um campo pode ser definido como uma rede ou uma configuração de relações objetivas entre posições. Essas posições são definidas objetivamente em sua existência e nas determinações que elas impõem aos seus ocupantes, agentes ou instituições, por sua situação \{situs\} atual e potencial na estrutura da distribuição das diferentes espécies de poder (ou de capital) cuja posse comanda o acesso aos lucros específicos que estão em jogo no campo e, ao mesmo tempo, por suas relações objetivas com as outras posições (dominação, subordinação, homologia, etc). (BOURDIEU, 1992, p. 60).

O campo da tatuagem em Cascavel se apresenta a partir de uma teia de relações sociais de posições. Essas posições são definidas através da experiência profissional de cada tatuador. Levando-se em consideração o tempo de atuação neste mercado, os tatuadores mais experientes (ditos mais antigos) exercem um poder sobre os tatuadores que começaram a tatuar mais recentemente.

Dentro do campo, para Bourdieu, há também o processo de acumulação de capital, do qual trata da quantidade de acúmulo de forças dos agentes que desempenha suas funções e suas posições dentro do campo. Os capitais envolvem volume e estrutura, ou seja, quantidade e tipo de capital. O autor identifica quatro principais tipos de capital: cultural, social, simbólico e o econômico. O capital cultural se apresenta como algo institucionalizado, incorporado e objetivo, sendo esse último relacionado com a posse de quadros,ou melhor obras de arte. O capital econômico está relacionado com os meios de produção e suas respectivas rendas. Enquanto que o social se mantém em relações de que o indivíduo dispõe, havendo a necessidade da manutenção dessas relações que se configuram como sociais. E o capital simbólico é aquele relacionado ao reconhecimento que corresponde toda a conjuntura de protocolos e etiquetas.

Quando se tem o capital econômico é muito mais propício conseguir os outros tipos de capitais, como por exemplo, o capital cultural que é objetivado e materializado em obras de arte em geral. E nessa pesquisa esse campo se apresenta a partir dessas relações de poder, através do capital econômico de cada agente que consegue se 
estabelecer e exercer poder tanto simbólico, quanto cultural e social com os demais agentes.

Esses tatuadores mais antigos são tidos como tatuadores profissionais e os mais novos como amadores $^{8}$. Os intitulados profissionais são os tatuadores que possuem estúdios, e em sua maioria concentrados no centro de Cascavel. Os amadores são os tatuadores domésticos, que tatuam em suas próprias residências ou na residência dos seus clientes, e estão localizados de forma periférica em relação ao centro. Para Costa (2004):

O advento do estúdio marca uma outra concepção de tatuagem. A tatuagem deixa a "periferia" e busca o "centro" da cidade, os pontos comerciais. A entrada da tatuagem no mercado é acompanhada de uma nova configuração no espaço de tatuar, onde a organização e a decoração representam e ao mesmo tempo contribuem para a construção de novos sentidos para a prática da tatuagem. (COSTA, 2004, p. 24)

A maior parte das etnografias lidas sobre essa temática do campo da tatuagem discorre sobre esse deslocamento da periferia para o centro. Constatei essa organização espacial dos estúdios e de seus tatuadores na cidade pesquisada ainda antes de ler estas etnografias. Essa divisão espacial se revela como um dos marcadores de distinção entre profissionais e amadores no contexto observado. Apresento aqui o que forma a base mínima das descrições etnográficas sobre o assunto: o espaço entre os estúdios, a distribuição espacial dos mesmos, a relação social dos tatuadores, bem como o significado da tatuagem para eles.

\section{OUTROS OLHARES SOBRE A TATUAGEM}

O estudo sobre a prática da tatuagem no Brasil expandiu nosso conhecimento etnográfico sobre este universo. Trabalhos primorosos como os de Andréa Fonseca (2003), Débora Leitão (2002) e Zeila Costa (2004) ampliaram os estudos ou as pesquisas sobre a tatuagem enfatizando como elemento recorrente em várias sociedades diferentes. A dissertação de Fonseca (2003) foi a que mais contribuiu com minha pesquisa, pois descreve as interações entre tatuador e o tatuado, expondo os valores e os códigos que transitam e são compartilhados dentro deste contexto.

${ }^{8}$ Essas expressões são provenientes das falas dos tatuadores que foram objetos da pesquisa, ou seja, os profissionais. 
Do ponto de vista da perspectiva de identidade, a autora compreende a tatuagem nos dias de hoje como uma normalidade se referindo a prática de tatuar como "uma forma a mais que o indivíduo utiliza para construir um sentido para a sua existência, fabricando sua própria transcendência pessoal." (FONSECA, 2003, p. 16). A autora reitera a importância que deve ser dada às chamadas táticas de legitimação no interior do universo da tatuagem:

É interessante constatar que através da vigilância da saúde se chega a toda uma estrutura punitiva de controle e regimento público de uma prática que, em seus albores e através de sua história, esteve fora do "status quo" dentro de formas e cenários tipicamente marginais. Assim, no momento, em que se regulamenta, também se legitima, mas dentro de normas de jogo que colocam limites à estrutura e funcionamento dessa prática. (FONSECA, 2003, p. 39)

Fonseca (2003) mostra a identificação da tatuagem não como um processo de identidade, mas como um processo de subjetividade. A busca dessa diferenciação só se realiza:

(...) como o resultado de três instâncias de motivação: o novo imaginário da tatuagem que fundamenta uma nova lógica desta prática, o mundo afetivo da tatuagem que reforça e estimula esse ato e os indivíduos que dentro de um campo de possibilidades sociais escolhem e assumem essa opção como uma via de individualidade, que, em conjunto, cria uma nova normalidade estética e vivencial no seio da sociedade ocidental contemporânea. (FONSECA, 2003, p. 140)

A autora ressalta também a construção de um projeto corporal, de ser tatuado e os significados sociais e pessoais que representam, onde "a pele se converte numa forma de expressão e construção do sujeito" (FONSECA, 2003, p.5). A prática da tatuagem é comparada a "um tecido que se forma no jogo das interações, nas influências interpessoais, na desenvoltura dos recursos expressivos, nas experiências que têm lugar dentro desse contexto.” (FONSECA, 2003, p. 46) fatores esses que moldam a pessoa que faz uso desta prática.

A autora faz também um apanhado geral da prática da tatuagem no Ocidente e o início da tatuagem moderna no Brasil. Por fim investiga o sentido de tatuar-se no qual encontrou resultados como expressão da subjetivação, busca da diferenciação, a necessidade de tatuar-se e a tatuagem atuando como uma nova dimensão do social. 
Não deixando de salientar a influência do fator estético no aumento da procura pela tatuagem, foi através da inserção no meio que ela encontrou "uma importante construção de sentido em torno das formas estéticas que são interpretadas sob processos pessoais e vivenciais e que constituem importantes indícios de sua identidade pessoal." (FONSECA, 2003, p. 142)

Outra bibliografia importante para este cenário é a de Débora Leitão (2002). A autora fez sua pesquisa em Porto Alegre-RS onde conseguiu apontar uma nova dimensão da prática da tatuagem na pós-modernidade com a alteração de público através do gênero. Um dos focos e objetivos centrais de sua investigação foi exatamente a observação das motivações das mulheres de camadas médias para o uso da tatuagem e o significado que essas dão pra tatuagem articulados à representação que essas mulheres têm dos padrões estéticos.

A autora expõe o crescimento considerável do mercado após a normatização dos estúdios. Essa normatização veio para melhorar a visão que se tinha de um estúdio e com isso, trouxe também a mudança das máquinas de tatuar, que passaram de manuais à elétricas. Com o aumento de estúdios aumentou também a sua clientela, inclusive de mulheres. As mulheres tinham receio de irem aos "estúdios" domésticos, mas depois da legalização, a procura das mulheres por tatuagens foi muito grande, invadindo assim um universo exclusivamente masculino. Ao abordar a temática de gênero a autora conseguiu direcionar uma analogia entre gênero, corpo e identidade feminina, demonstrando o papel do embelezamento e da estética no processo, muitas vezes relacionado a outras intervenções de embelezamento.

Costa (2004) descreve a prática da tatuagem na cidade de Florianópolis/SC sob o prisma das mudanças no campo da tatuagem no âmbito de aproximadamente duas décadas "entre elas, está à passagem da clandestinidade - e seus significados metafóricos associados à marginalidade - para a visibilidade, seja dos estúdios - um espaço de sociabilidade - ou dos corpos tatuados que circulam pelas ruas" (COSTA, 2004, p. 112). A autora também constatou a mudança no universo dos tatuadores a partir do momento que tatuadores amadores que tatuavam nas ruas ou em suas casas, tornaram-se profissionais, abrindo salas comerciais nos centros das cidades sob a forma de estúdios. Para a autora, a mudança no status do tatuador, agora um profissional, levou à constituição de uma preocupação em diferenciar amadores e profissionais, envolvendo noções de arte. 
Mais do que simplesmente uma forma de manter a independência, talvez a percepção dessa necessidade de 'abrir uma loja no centro' já fale de um novo momento que começava a viver a tatuagem no Brasil. A abertura dos estúdios, ou lojas, como chamou Stoppa, pode ser considerada parte de um processo de profissionalização que vem ocorrendo com a tatuagem nos últimos anos. (COSTA, 2004, p. 24)

A imagem de amador alterou-se para profissional a partir da normatização regida pelo Estado e, em seguida remeteu-se a imagem do profissional a de artista. Os profissionais passaram a representar-se como artistas e à sua profissão como arte ao mesmo tempo em que foram levados a executá-la segundo padrões médicos de inspeção e higiene.

O campo da tatuagem num âmbito geral, que a princípio parecia ser fundamentalmente masculino, se evidenciou como algo fascinante para muitas mulheres, as quais constituem, na atualidade, seus maiores clientes. São elas que movem financeiramente os estúdios, pois, escolhem habitualmente desenhos pequenos que levam pouco tempo para serem feitos, do qual também não precisão dispor de muita técnica para fazê-los. Em contrapartida, a partir dos discursos acionados dos tatuadores são os desenhos maiores, todavia, escolhidos em sua maioria pelos homens, aqueles que são mais caros, valorizados e considerados artísticos pelos tatuadores e até mesmo pelos tatuados.

Fonseca (2003) faz uma abordagem sobre uma tabela com a classificação das pessoas que possuem tatuagens por gêneros entre os anos 1996 a 2002 no estúdio onde ela fez sua etnografia. A autora afirma que a correlação de sexo mudou ostensivamente durante este período de tempo e que, o índice de pessoas tatuadas por grupos de idade aumentou consideravelmente pelas faixas etárias acima dos 39 anos de idade. Além dessa distribuição de gênero e idade ela aborda a localização corporal das tatuagens em mulheres e homens através de gráficos, onde confirma que as escolhas do local são visivelmente norteadas pelos moldes sexuais:

No caso das mulheres, suas preferências são a parte baixa das costas, representando entre 20 e $30 \%$ de suas escolhas, seguidas pelo pescoço, canela, quadril e barriga, e, em proporções menores e oscilantes, outros locais como os braços, peito e tornozelo. Em contraste, os homens se inclinam pelos braços, que constituem $45 \%$ de sua escolha, as costas, que representa $20 \%$, seguido da canela, com $10 \%$, e, em quantidade menor, os outros locais do corpo. (FONSECA, 2003, p. 91) 
A autora faz uma abordagem sobre os estilos de desenhos escolhidos entre mulheres e homens. Segundo a autora as mulheres escolhem os desenhos como: tribal, fada, coração, flor, índio, aranha, escorpião, animais marinhos, golfinho, cavalo, anjo, astros, lua, sol, estrela, oriental entre outros. Já os homens escolhem: tribal, índio, caveira, esqueleto, crânio, pantera, tigre, sereia, mulher, palhaço, comics, aranha, cobra, demônio, animais felinos, águia, dragão, máscaras, ideogramas entre outros.

Outra hipótese que também verifiquei ser falsa quando iniciei minha investigação, foi julgar que este campo era essencialmente habitado por pessoas mais novas. Os mais novos habitam o universo da tatuagem sim, mas não são sua exclusividade, há uma boa quantidade de pessoas com uma faixa etária maior que se tatuam tanto quanto aqueles.

Percebi que tais hipóteses eram oriundas de um senso comum sobre a tatuagem e, depois de rejeitá-las, coube a tarefa de procurar saber e de compreender quais os significados que cada um destes grupos de tatuados apresentava para suas tatuagens. Desta forma, trago para este artigo o âmbito da tatuagem em Cascavel, como ele está organizado, quem são e onde estão localizados os estúdios. Neste contexto, partindo do geral para o individual apresento a configuração do campo da tatuagem em Cascavel.

\section{O CAMPO DA TATUAGEM EM CASCAVEL}

Através de contatos telefônicos e de algumas visitas a Cascavel consegui visualizar o panorama geral de alguns estúdios, os quais já se encontram legalizados e instalados em salas e espaços adequados para realização de suas atividades ${ }^{9}$. Uma visão mais ampla, contudo, precisaria incluir o que tradicionalmente se denomina de estúdios domésticos. Todos os estúdios observados estão localizados na região central de Cascavel. As ruas em destaque no mapa, na cor azul, correspondem as principais vias de acesso ao centro e algumas delas atravessam a cidade inteira de uma ponta à outra.

\footnotetext{
${ }^{9}$ Esses espaços se configuram como adequados tanto pela vigilância sanitária quanto pelo tatuador, que prezam pelo ambiente limpo, higiênico e asséptico para a realização de serviços prestados a seres humanos, onde envolve todo um aparato próprio para que nada de errado ocorra.
} 


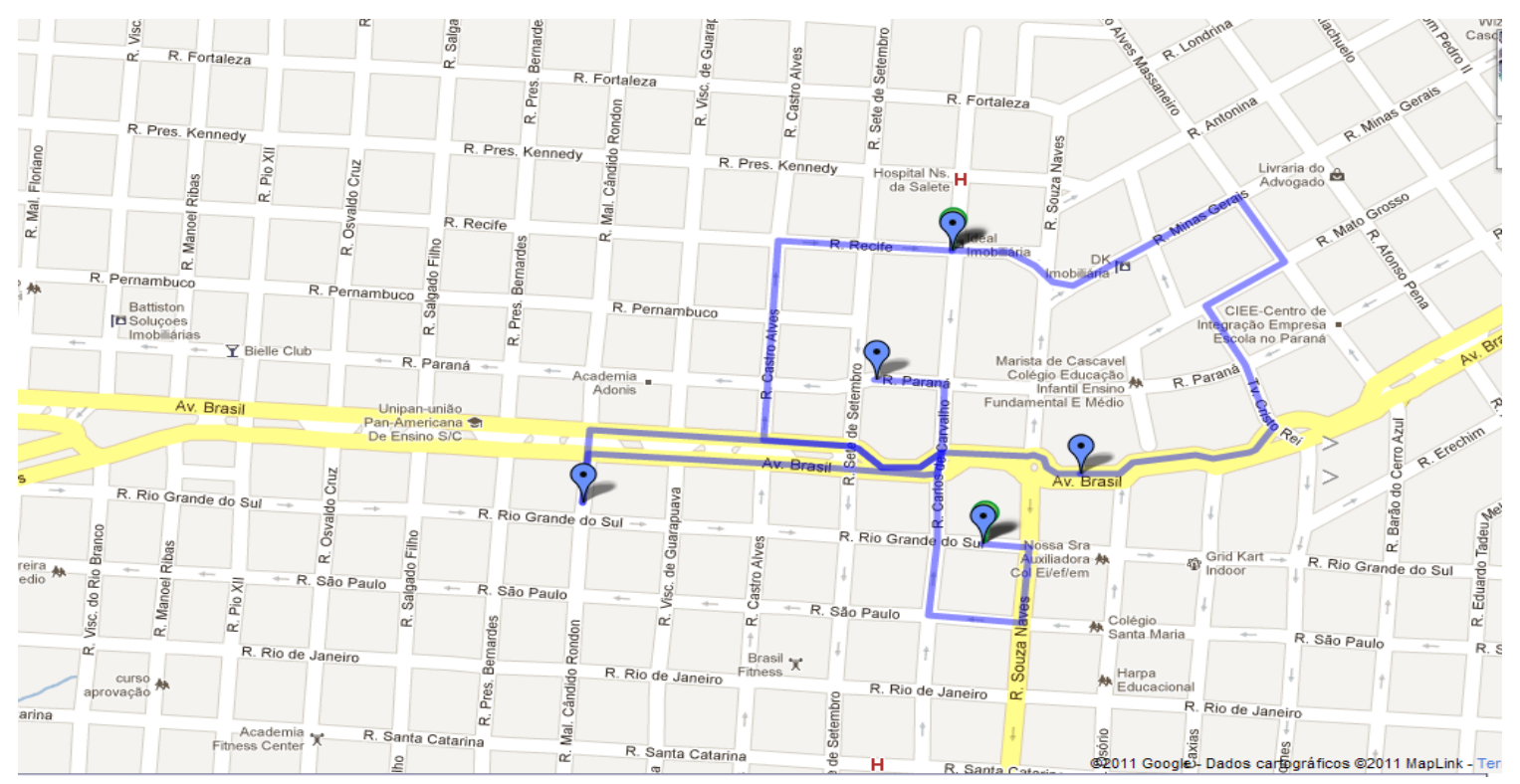

FIGURA 1. Trajetos entre os estúdios.

FONTE: Google Maps

Do modo como está configurado o espaço da tatuagem podemos ter a dimensão de como este campo é restrito. A forma como estão localizados os estúdios indica o "poder simbólico" que uns exercem sobre os outros. Na região central há uma ordem de espaço que depende da quantidade de tempo que o tatuador está no mercado. Alguns amadores até conseguem abrir um estúdio, quando há alguma sala vazia, no entanto, o tempo de permanência é curto ${ }^{10}$.

Essa forma de organização é frequentemente utilizada neste ramo, onde os profissionais têm uma permanência no centro do círculo e os amadores permanecem do lado de fora, nos arredores do centro. Desse modo, os que atuam no centro são os que exercem maior influência, obtendo assim, uma maior clientela.

Procurei saber como os estúdios têm se organizado, levando em consideração o aumento da demanda por tatuagens na cidade. A procura por esta prática é o que permite a expansão dos estúdios. Afinal, a prática da tatuagem é um adorno de alto valor. Considerando a expansão e a ampliação dos estúdios, outro fator que deve ser pensado é o aumento da concorrência. Para os tatuadores a concorrência não é vista como um empecilho ou algo que venha a prejudicá-los, a não ser que essa concorrência parta para

\footnotetext{
${ }^{10}$ Essas informações foram obtidas juntamente com os tatuadores daquela região, e até mesmo em conversa informal com uma pessoa que possui seu estúdio "caseiro", ou melhor, doméstico, como eles mesmos denominam, numa região mais afastado do centro. Disse que tentou se manter no centro pra ter uma clientela maior mais que não consegui, tendo assim, que "abrir" um estúdio na própria casa.
} 
o lado pérfido, no qual tatuadores cobram preços muito abaixo para a execução do trabalho.

O mesmo constatou Costa (2004):

Entre os tatuadores entrevistados, com exceção de dois deles, há um tipo de acordo tácito sobre a valorização das tatuagens, que são cobradas principalmente por hora de trabalho, valor que pode sofrer modificações dependendo da época do ano, durante o inverno, quando a demanda é menor, fazem descontos nos preços (COSTA, 2004, p. 91).

Mesmo que a distância entre os estúdios seja muito pequena, a concorrência parece não servir de agente regulador. A qualidade do trabalho do qual muitas vezes é atrelada a arte é o que diferencia um estúdio e outro. O concorrente, na maioria das vezes, não se torna um obstáculo, na medida em que, as propostas dos estúdios são diferentes e parece haver público para todos nos dias atuais.

Os estúdios domésticos são estúdios que não possuem a Licença Sanitária, ou seja, não estão enquadrados nas normas estabelecidas por lei, portanto, ilegais perante o Estado. A prática da tatuagem só pode ser efetuada em ambiente particular e que tenha uma construção dentro das normas e adequada para tal fim, o que torna impedida a execução em ambientes diversos a estes.

Quanto aos valores estabelecidos para as tatuagens, pude perceber que oscilam a partir dos critérios estabelecidos como o tamanho, complexidade e natureza do desenho ${ }^{11}$. Mas, esta variação não influencia na relação entre os tatuadores profissionais, os quais seguem certo padrão.

O que diverge é a problemática dos estúdios domésticos que, em função de não terem que pagar aluguéis de salas e atuarem na ilegalidade quanto às leis e normas estabelecidas ao adequado funcionamento de um estúdio de tatuagens, acabam trabalhando com valores muito abaixo. Este tipo de situação gera transtornos não apenas aos tatuadores legalizados, mas, sobretudo, aos clientes desavisados que, muitas vezes, acabam sofrendo efeitos colaterais e sequelas indesejadas.

Esta série de procedimentos higienizadores da vigilância sanitária foi tomada para garantir o direito de obterem a licença de funcionamento. As medidas foram adotadas aqui no Paraná através da Portaria CVS-12, de 30 de Julho de 1999 e Resolução SESA n.

\footnotetext{
${ }^{11}$ A qualidade do material também interfere no valor a ser cobrado por cada sessão, entre elas estão as tintas das quais preferem as importadas do que as nacionais, já que essas por sua vez, são monopolizadas por duas empresas de um mesmo dono. Preferem comprar as importadas mesmo que elas sejam "proibidas" no país.
} 
0126/2007 $7^{12}$. Desse modo, o Estado exerce um controle desta prática na sua institucionalização que, por se tratar de uma técnica realizada em seres humanos e que põe em risco a vida destes, há uma necessidade do Estado de regulamentar e impor uma série de cuidados e exigências, não apenas de higiene, mas, também, éticas.

Segundo $\operatorname{Marcos}^{13}$, um dos tatuadores entrevistados, o Brasil representa hoje um dos únicos países no mundo a regulamentar essa prática a nível governamental. Ressalta, contudo, a necessidade de se manter cuidados básicos e imprescindíveis na utilização das tintas. Entre estes, destaca a importância do emprego de biqueiras descartáveis e o cuidado com o armazenamento.

Para o tatuador a normatização além do caráter de regular é fundamental, pois, os tatuadores ganham um maior reconhecimento social aumentando assim, o público que atribui uma maior legitimidade no seu trabalho. Pode-se dizer que isto facilita a sedimentação da imagem do tatuador como um profissional.

Tal perspectiva, aos olhos do tatuador, possibilita a abertura de duas dimensões: uma positiva e outra negativa. $\mathrm{O}$ aspecto positivo é que, muitas pessoas passam a encarar a tatuagem como algo sério e sem riscos, deixando de lado o medo de contaminações, etc. $\mathrm{O}$ aspecto negativo é que, desse modo, a prática da tatuagem sofre um processo de popularização, no qual pessoas, muitas vezes, buscam este artifício simplesmente por ser algo que está na moda ou porque identificam seus ídolos com suas tatuagens, etc.

Este modo de compreensão da tatuagem, contudo, constitui, para o tatuador, o lado sombrio da arte. Para os tatuadores profissionais, a tatuagem é uma arte e seu potencial artístico deve ser aproveitado, o que de fato é raro, dado que o procedimento é caro e o gosto pessoal do cliente nem sempre combina com as aspirações e habilidades artísticas do tatuador.

Dessa maneira, é possível verificar a noção de ao menos dois tipos de tatuadores: os tatuadores profissionais que são vistos como bons tatuadores e fazedores de $\operatorname{arte}^{14}$. Em oposição a estes, estão os tatuadores de cadeia, termo utilizado no universo da tatuagem para tatuador que é amador o qual não está apto para realizar uma arte, pois suas técnicas

12 Esta portaria e resolução seguem o regimento da Lei instituída no âmbito do Estado do Paraná para regulamentar e fiscalizar os estúdios de tatuagem, na medida em que estes são estabelecimentos que dizem respeito à saúde, tanto coletiva quanto individual.

${ }^{13}$ Marcos é dono e tatuador da Colors Steel Blood no qual estendi um tempo maior para a pesquisa, por conhecê-lo anteriormente. Sua trajetória de vida também passou por estúdios clandestinos na própria residência, após esse período passou algum tempo em Florianópolis fazendo tatuagem na praia.Voltou e se instalou no centro da cidade onde mantém seu estabelecimento até então.

${ }^{14}$ Segundo alguns tatuadores,esses são "fazedores de arte" por que passaram por todo o processo que um tatuador doméstico traça até chegar a este plano. 
são de baixa qualidade. A qualidade artística só é alcançada através de experiência ao longo dos anos, como demonstra Leitão (2003) - aliás, este trabalho, dentre outros, mostra como esta aspiração é corrente no universo da tatuagem.

Os tatuadores constroem uma diferenciação interna ao grupo a partir desta noção de arte e de ofício artístico. O tatuador de estúdio considera-se um profissional e um artista e se coloca em oposição ao amador que é considerado como "tatuador de cadeia". O que difere entre eles não é somente a qualidade do trabalho realizado, mas, sobretudo a existência de um campo de concorrência. Assim, quando um tatuador aponta outro de fazer um trabalho mal feito, com isso, ele acaba levantando dúvidas sobre a higiene do lugar, por exemplo.

Além disso, as características demonstradas acima denotam a força do discurso artístico em torno da tatuagem, como a prática do Free Hand ${ }^{15}$, a presença da pintura e de outras técnicas criativas nos estúdios no desejo pela seleção dos clientes, a qualificação estética e de originalidade de seu trabalho e do trabalho de outros tatuadores, na classificação dos desenhos em estilos artísticos, na valorização da experiência do tatuador e, sobretudo, na classificação chancelada pelo Estado entre profissionais e não profissionais, legais ou ilegais.

\section{CONSIDERAÇÕES FINAIS}

O objetivo deste trabalho foi estudar o campo da tatuagem na cidade de Cascavel, o qual se apresentou a partir de uma teia de relações de posições, entre os tatuadores que querem se estabelecer como profissionais e os que já estão nessa condição. Para alcançar meus objetivos busquei compreender como ocorre este processo de distribuição espacial e simbólica dos profissionais e os amadores.

O Estado entra em ação para regulamentar o ofício do tatuador e ao mesmo tempo promove uma consciência de um ambiente limpo e higienizado tal qual devem ser os procedimentos com seres humanos que põem em risco a vida destes. Com isso, regulamenta a prática da tatuagem tendo um controle social dos tatuadores. Embora a

\footnotetext{
${ }^{15}$ Esta prática é normalmente atribuída à arte por ser uma técnica que depende de muito tempo para ser feita. O cliente fala sobre como quer o desenho e o tatuador desenha com pincel na pele e modifica na medida em que o tatuado pede, assim, entram num consenso e o desenho começa a ser tatuado a partir desta negociação. No universo da tatuagem essa prática é feita somente pelos profissionais.
} 
legislação não declare uma profissão de tatuador e sim de profissional autônomo, a relação evoca um discurso de profissionalismo, que é mantida por eles.

Essa "profissão" legitimada pela legislação e afirmada pelos seus atores ganha mais intensidade quando é voltada para a arte. O tatuador profissional se considera um artista, no qual insere no corpo do indivíduo seus desenhos.

O discurso sobre a arte é muito forte entre os tatuadores, eles buscam ser reconhecidos como artistas através da valorização da técnica e estética de seus trabalhos. Embora afirmem que a tatuagem venha se vulgarizando, buscam conquistar um público que reconheça o seu valor de arte.

As técnicas para desenvolver um desenho são evocadas por eles como um modo de diferenciação daqueles que não são profissionais. A situação ideal seria aquela em que o conhecimento e os valores partilhados por tatuador e tatuado dessem sentido de afirmação da subjetividade para o indivíduo e de objetivação da arte técnica e profissional para o tatuador.

Na outra ponta desse universo estão os tatuadores ilegais, referenciados também como amadores. Estes estão sujeitos a carga simbólica produzida no interior do campo, cujos valores de arte encontram-se inacessíveis para os amadores.

Além disso, a normatização imposta pelo Estado se torna uma barreira simbólica e mais do que isso, punitiva. A trajetória de vida de cada tatuador é ao mesmo tempo individual e coletiva, pois seus objetivos se relacionam buscando o reconhecimento de um status de arte. Em suma, pude concluir através desse trabalho, que:

1. Os tatuadores se organizam em um campo, onde relações de reciprocidade, acusação, afinidade e hostilidade são travadas. Nesse campo há também a produção e partilha de significados próprios de seus agentes.

2. As trajetórias de vida individuais de cada um dos tatuadores apresentam constâncias como as dificuldades no início da carreira, o aprendizado da técnica, o apoio do círculo social para a profissionalização e a consolidação dos esforços na montagem do estúdio. Além disso, a projeção de seu trabalho como ofício artístico também é recorrente. Estas trajetórias também estão inseridas no contexto das mudanças incididas em nível maior, como as normatizações da prática da tatuagem e a sua popularização nas últimas duas décadas.

3. As representações que circulam no campo da tatuagem dão conta de aspectos duais, tais sejam: profissionais e não profissionais, artistas e amadores, legais e ilegais. Essa configuração se liga às mudanças no campo brasileiro desde os anos 1970, 
consolidando-se no final dos anos 1980, com as regulamentações higiênicas para a tatuagem. A passagem da clandestinidade à profissionalização partiu o campo dos tatuadores entre aqueles que fizeram a passagem e aqueles que permaneceram à margem. Essa marginalidade dos estúdios domésticos se mostra não só no nível simbólico, mas geográfico, quando se observam nada menos do que seis de dez estúdios legais situados no centro da cidade, restando aos demais as regiões mais periféricas.

4. A higiene é também adotada como reforço da representação de profissional. Não raro a decoração e instrumental pode confundir o visitante desavisado com uma clínica médica. Chancelados pelo Estado, os tatuadores profissionais projetam em sua prática a assepsia necessária e não presente nos ilegais. No entanto, a condição higiênica de profissional parece concorrer com a auto representação de artista, gerando reações de valorização das expressões artísticas em detrimento das profissionais-higiênicas, como no caso do estúdio que, durante a pesquisa, passou de inteiramente branco a uma paleta de cores escuras e vivas.

5. O discurso artístico é o principal referencial para a manutenção de um campo de hegemonia entre os tatuadores. A sua arte está manifesta nas paredes dos estúdios, nas atividades de pintura ou outras atividades criativas exercidas pelos tatuadores e como uma constante em suas falas de legitimação, diferenciando os artistas dos amadores. Também a técnica do free hand e a confecção dos próprios desenhos acentuam este imperativo no campo da tatuagem.

6. A popularização da tatuagem provoca reações ambíguas, que envolvem o otimismo diante de uma perspectiva de aceitação social da prática e o receio diante do risco da banalização da prática artística da tatuagem, tornando-se comercial e tão somente produto de consumo. Além disso, a perspectiva de mudanças significativas põe em risco hegemonias para alguns e representa possibilidades de ascensão para outros no campo da tatuagem.

\section{REFERÊNCIAS BIBLIOGRÁFICAS}

BOURDIEU, Pierre. A economia das trocas simbólicas. 3 ed. São Paulo: Perspectiva, 1992. 
COSTA, Zeila. Do Porão ao Estúdio: trajetórias e práticas de tatuadores e transformações no universo da tatuagem. Florianópolis 2004. Dissertação de Mestrado Universidade Federal de Santa Catarina, 2004.

FONSECA, Andréa Lissett P. Tatuar e ser tatuado: Etnografia da Prática Contemporânea da Tatuagem, Estúdio: Experience Art Tattoo. Dissertação (Mestrado em Antropologia Social) - Universidade Federal de Santa Catarina, Florianópolis, 2003.

LEITÃO, Débora Krischke. O Corpo Ilustrado: um estudo antropológico sobre usos e significados da tatuagem contemporânea. Dissertação de Mestrado - Universidade Federal do Rio Grande do Sul, Porto Alegre, 2002.

MAUSS, Marcel. As Técnicas Corporais In: Mauss, Marcel, Sociologia e Antropologia. São Paulo: EDUSP, 1974, pp. 209-233.

PARANÁ (Estado). Resolução SESA n. 0126/2007 DE JULHO DE 1999. Disponível em:<http://www.sesa.pr.gov.br/arquivos/File/Legislacao/estudual_resolucao/07RSESA _126_tatuagem_piercing.pdf $>$ Acessada em agosto de 2011. 